\title{
AS NOVAS TECNOLOGIAS NA PRÁTICA PEDAGÓGICA SOB A PERSPECTIVA CONSTRUTIVISTA
}

Flavia Rezende, Núcleo de Tecnologia Educacional para a Saúde, UFRJ

Neste trabalho refletimos sobre a utilização das novas tecnologias da informação e da comunicação no processo educativo sob a perspectiva construtivista, apontando desafios para a elaboração de materiais didáticos e para a prática pedagógica. Inicialmente, apresentamos uma visão panorâmica de como o construtivismo pode afetar os materiais didáticos que incorporam as novas tecnologias; em seguida, são tecidas considerações sobre as transformações necessárias de alguns elementos da prática pedagógica, como o papel do professor, o planejamento e a avaliação educacional em projetos de inovação tecnológica na escola, sob a mesma perspectiva. A principal contribuição do artigo é apresentar os encaminhamentos que têm sido dados a essa discussão nas literaturas nacional e estrangeira, o que pode ser útil a quem deseja aproximar-se das tendências atuais da introdução das novas tecnologias na educação.

\section{Introdução}

$\mathrm{Na}$ virada do século, não se trata mais de nos perguntarmos se devemos ou não introduzir as novas tecnologias da informação e da comunicação no processo educativo. Já na década de 80, educadores preocupados com a questão consideraram inevitável que a informática invadisse a educação e a escola, assim como ela havia atingido toda a sociedade (Monteiro \& Rezende, 1993). Atualmente, professores de várias áreas reagem de maneira mais radical, reconhecendo que, se a educação e a escola não abrirem espaço para essas novas linguagens, elas poderão ter seus espaços definitivamente comprometidos (Kawamura, 1998).

Sabemos, entretanto, que os meios, por si sós, não são capazes de trazer contribuições para a área educacional e que eles são ineficientes se usados como o ingrediente mais importante do processo educativo, ou sem a reflexão humana. Mesmo aqueles que defendem a tecnologia, proclamando apenas seus benefícios, deveriam considerar que a tecnologia educacional deve adequar-se às necessidades de determinado projeto político-pedagógico, colocando-se a serviço de seus objetivos e nunca os determinando.

Embora seja verdade que a tecnologia educacional não irá resolver os problemas da educação, que são de natureza social, política, ideológica, econômica e cultural, essa constatação não nos pode deixar sem ação frente à introdução das inovações tecnológicas no contexto educacional. Ainda é preciso continuar pesquisando sobre o que as novas tecnologias têm a oferecer à educação, para que tenhamos condições de formar uma visão crítica fundamentada sobre o seu uso.

Nesse processo, o mais importante é considerar essa oportunidade como fundamental para questionarmos o paradigma tradicional de ensino ainda hegemônico no contexto educativo. O ideal é aproveitar este momento para incorporar novos referenciais teóricos à 
elaboração de materiais didáticos ou à prática pedagógica até porque as novas tecnologias podem propiciar novas concepções de ensino-aprendizagem.

Esse deve ser o grande desafio em qualquer projeto de inovação tecnológica na área educacional. Sabemos que, se a tecnologia não recebe o tratamento educacional necessário, 0 alcance do projeto tende a ser efêmero, não alterando o cotidiano de professores e alunos nem trazendo contribuições ao processo de ensino-aprendizagem (Candau, 1991).

A introdução de novas tecnologias na educação não implica necessariamente novas práticas pedagógicas, pois podemos com ela apenas vestir o velho com roupa nova, como seria o caso dos livros eletrônicos, tutoriais multimídia e cursos a distância disponíveis na Internet, que não incorporam nada de novo no que se refere à concepção do processo de ensinoaprendizagem. Dessa forma, as novas tecnologias são usadas apenas como instrumento (Pretto, 1996), o que tende a ser inócuo na educação se não repensamos os demais elementos envolvidos nesse processo. Nesses termos, "sua utilização acaba por resultar quase sempre em aulas em vídeo iguais às da escola de hoje, ou a textos em microcomputadores, interativos e auto-instrutivos, mais limitados que os livros existentes nas estantes escolares" (Kawamura, 1998).

Acreditar, entretanto, que novas práticas pedagógicas implicam o uso de novas tecnologias, confiando à tecnologia educacional a renovação da educação, seria uma visão extremamente tecnicista do processo educativo. Para Dillon (1996), acreditar que qualquer nova tecnologia nos oferece os meios de resolver nossos problemas educacionais é fazer parte da nova tecnocracia. Segundo ele, essa nova tecnocracia não é muito diferente da velha tecnocracia das máquinas de ensinar de Skinner, mesmo que admitamos avanços teóricos de lá para cá.

Se as novas tecnologias não implicam novas práticas pedagógicas nem vice-versa, aparentemente poderíamos dizer que não há relação entre essas duas instâncias. Entretanto, isso não é necessariamente verdade, se considerarmos que o uso das novas tecnologias pode contribuir para novas práticas pedagógicas desde que seja baseado em novas concepções de conhecimento, de aluno, de professor, transformando uma série de elementos que compõem o processo de ensino-aprendizagem.

As seções seguintes procuram ilustrar de que forma a utilização das novas tecnologias poderia contribuir para a elaboração de materiais didáticos e para a prática pedagógica. Essa separação entre a tecnologia e o contexto educativo apenas facilita a exposição das idéias, mas a concepção de tecnologia educacional aceita atualmente é aquela que considera como tecnologia tudo o que os professores fazem a cada dia para enfrentar o problema de ter de ensinar a um grupo de estudantes determinados conteúdos com determinadas metas (Sancho,1998), independentemente do uso de meios tecnológicos para esse fim.

\section{A ABORDAGEM CONSTRUTIVISTA COMO ORIENTADORA DE PROJETOS DE INOVAÇÃO TECNOLOGICA NA EDUCAÇÃO}

O principal aspecto a ser questionado sobre a elaboração de materiais didáticos mediatizados por novas tecnologias da informação e da comunicação é a sua contribuição para 
novas concepções da aprendizagem. Essa questão é polêmica, visto que parece não haver um ponto de vista único entre os especialistas da área.

Carraher (1992), referindo-se à informática, considera que sua contribuição é (apenas) de ordem tecnológica e não conceitual, o que significa que ela não oferece subsídio para a elaboração de novas idéias acerca dos processos de aprendizagem ou ensino.

Desde que usadas como fundamento do processo de ensino-aprendizagem e não como mero instrumento, Pretto (1996) admite, numa visão oposta, que as novas tecnologias podem representar uma nova forma de pensar e sentir ainda em construção, vislumbrando, assim, um papel importante para elas na elaboração do pensamento.

Vista dessa perspectiva, a concepção de materiais didáticos que incorporem novas tecnologias, capazes de oferecer uma reestruturação do processo de aprendizagem, depende do esforço de relacionar novas abordagens teóricas sobre a aprendizagem a seu desenho instrucional. Tomando, porém, como exemplo a pesquisa no campo da informática educativa nos últimos dez anos, pode-se observar que a transferência de descobertas nas ciências cognitivas e sociais para a prática do planejamento de materiais didáticos raramente é um processo tão direto (Dillon, 1996), o que representa o grande desafio para os projetos de inovações tecnológicas na escola.

O construtivismo tem sido ultimamente a abordagem teórica mais utilizada para orientar o desenvolvimento de materiais didáticos informatizados, principalmente o de ambientes multimídia de aprendizagem (Boyle, 1997). Podemos considerá-lo como um guarda-chuva que tem dado origem a diferentes propostas educativas que incorporam novas tecnologias, às vezes de forma implícita, às vezes de forma explícita.

O fato de a abordagem construtivista ser hoje predominante não significa uma tendência única refletida nos materiais didáticos, mesmo porque a idéia de construção do conhecimento está presente na obra de vários autores, como Piaget, Vygotsky, Wallon, Paulo Freire, Freud, entre outros (Grossi \& Bordin, 1993, citado por Bastos, 1998) e, dependendo de qual deles seja o referencial eleito, configura-se uma proposta pedagógica um pouco diferenciada.

Apesar das diferenças entre as concepções teóricas desses autores sobre 0 construtivismo, há elementos comuns que são fundamentais. Talvez o mais marcante seja a consideração do indivíduo como agente ativo de seu próprio conhecimento, o que no contexto educativo desloca a preocupação com o processo de ensino (visão tradicional) para o processo de aprendizagem. Na visão construtivista, o estudante constrói representações por meio de sua interação com a realidade, as quais irão constituir seu conhecimento, processo insubstituível e incompatível com a idéia de que o conhecimento possa ser adquirido ou transmitido. Assumir esses pressupostos significa mudar alguns aspectos centrais do processo de ensino-aprendizagem em relação à visão tradicional (QUADRO 1). 


\section{QUADRO 1}

\section{Abordagens tradicional e construtivista da aprendizagem}

\begin{tabular}{ll}
\hline ABORDAGEM TRADICIONAL & ABORDAGEM CONSTRUTIVISTA \\
Enfoque no professor & Enfoque no aluno \\
Enfoque no conteúdo & Enfoque na construção individual de \\
& significados
\end{tabular}

A mente do aluno funciona como uma A aprendizagem é uma construção do aluno "tabula rasa"

sobre conhecimentos prévios

O aluno é receptor passivo de Ênfase no controle do aluno sobre sua conhecimento aprendizagem

Memorização de conhecimento

Habilidades e conhecimento são
$\begin{aligned} & \text { desenvolvidos no contexto onde serão } \\ & \text { utilizados }\end{aligned}$

À medida que professores e elaboradores de materiais didáticos que incorporam as novas tecnologias apropriam-se dos pressupostos teóricos construtivistas, estes tomam uma feição diferenciada, parecendo mesmo apoiarem-se em abordagens diferentes. Isso pode, de fato, acontecer porque não há uma correlação perfeita entre pressupostos teóricos do construtivismo e as características técnicas de materiais didáticos.

A transferência da teoria para a prática do desenho instrucional não é fácil nem óbvia e, muitas vezes, as iniciativas de usar os pressupostos construtivistas no desenvolvimento de ambientes tecnológicos de ensino-aprendizagem ficam aquém da intenção inicial. Procurando colocá-los em prática, materiais didáticos que incorporam as novas tecnologias têm como característica principal passar para as mãos do estudante o controle de sua aprendizagem, tornando possível uma interação na qual ele "ensina" à tecnologia (Valente, 1993) mais do que aprende com ela.

A epistemologia construtivista relaciona-se fundamentalmente com a idéia de construção, o que no planejamento de materiais didáticos informatizados pode ser traduzido na criação de ambientes de aprendizagem que permitam e dêem suporte à construção de alguma coisa ou ao envolvimento ativo do estudante na realização de uma tarefa, que pode ser individual ou em grupo, e a contextualização dessa tarefa. Para isso, oferecem ferramentas e meios para criação e manipulação de artefatos ao invés de apresentarem conceitos prontos ao estudante.

Para Morgan (1995), a oposição entre os papéis ativo e passivo do aluno frente à aprendizagem é insuficiente. Com o conceito de abordagem profunda, a autora pretende dar ênfase à apropriação das estratégias metacognitivas pelo aluno na interação com materiais didáticos informatizados. Essa perspectiva quer marcar a diferença em relação ao processo tradicional de ensino, no qual o aluno interage com o conteúdo visando apenas à avaliação. Para que o aluno desenvolva uma abordagem profunda à sua aprendizagem, é necessário que ele adquira a consciência do que consiste aprender, etapa que será fundamental no processo. 
Em outras palavras, o mais importante é aprender como aprender, como construir e refinar novos significados. A metacognição pode, assim, ser associada à resolução de problemas, quando, além de refletir sobre a solução, o indivíduo reflete sobre suas próprias abordagens ao problema. Essa reflexão pode gerar estratégias alternativas mais produtivas. $\mathrm{O}$ alvo do processo educativo passa a ser a habilidade de reflexividade (Cunningham et al., 1993) e não o de memorização.

Em termos mais técnicos, Perkins (1992) delineia cinco elementos que podem fazer parte de ambientes informatizados de aprendizagem ("bancos de informação", "utensílios para processamento de símbolos", "ferramentas de construção", "bancos de fenômenos" e "gerenciador de tarefas") e discute o impacto do construtivismo sobre esses ambientes, dependendo de quais deles são selecionados. Os bancos de informação são depósitos de informação, como livros-texto, livros de referência ou banco de dados informatizados. Utensílios para processamento de símbolos são superfícies para manipulação de símbolos como, por exemplo, blocos de notas ou processadores de texto. Ferramentas para construção são conjuntos de componentes que fornecem materiais para atividade de construção como, por exemplo, uma linguagem de programação. Bancos de fenômenos são exemplos de fenômenos a serem estudados. Finalmente, gerenciadores de tarefas estabelecem as tarefas de aprendizagem, monitoram o progresso e avaliam os resultados.

A maior ênfase num desses componentes do que em outros pode levar a diferentes configurações de projetos de inovação tecnológica na educação. Uma sala de aula tradicional, por exemplo, prioriza os bancos de informação e os utensílios para processamento de símbolos. O professor tradicional, em geral, faz o papel de gerenciador de tarefas. Em software educacionais do tipo tutoriais ou de exercício e prática, o computador tem um forte papel de gerenciador de tarefas, uma vez que estabelece a seqüência de tópicos a serem trabalhados e os objetivos a serem alcançados.

Perkins (1992) classifica como construtivista o ambiente de aprendizagem que ofereça ao aluno ferramentas de construção e a possibilidade de interação com a realidade, muitas vezes simulada. O computador é usado como ferramenta para gravar, analisar e comunicar interpretações da informação entre os participantes. O estudante deverá construir seu próprio banco de informações e assumir a responsabilidade pelo gerenciamento das tarefas de aprendizagem.

Se, por um lado, o construtivismo tem sido considerado, hoje em dia, uma abordagem mais adequada para se compreender a cognição humana, como pode ser visto pela ampla aceitação que alcançou recentemente, por outro, é verdade que esse referencial permanece ainda mais descritivo do que prescritivo (Jonassen, 1991) e que há necessidade de pesquisa para testar, validar e/ou alterar as perspectivas de desenho instrucional que ele oferece. Algumas tentativas têm sido feitas nesse sentido. A seção seguinte oferece um panorama das principais alternativas propostas pelos especialistas da área. 


\section{Materiais Didáticos e as Novas Tecnologias na Perspectiva Construtivista}

Na perspectiva construtivista, o tecnólogo educacional deve ter todo o cuidado para que o desenho instrucional dos ambientes de aprendizagem atenda aos seus pressupostos teóricos, pois, sendo a informática uma ferramenta que funciona segundo uma linguagem binária, ela se ajusta muito mais facilmente a pressupostos comportamentalistas do tipo "sim/não", "certo/errado", "seguir/voltar" do que a padrões de interação criativos que explorem o raciocínio e a criatividade do estudante.

As principais características das novas tecnologias da informação e da comunicação presentes na elaboração de materiais didáticos e projetos fundamentados na abordagem construtivista são: (1) a possibilidade de interatividade; (2) as possibilidades que o computador tem de simular aspectos da realidade; (3) a possibilidade que as novas tecnologias de comunicação, acopladas com a informática, oferecem de interação a distância e (4) a possibilidade de armazenamento e organização de informações representadas de várias formas, tais como textos, vídeos, gráficos, animações e áudios, possível nos bancos de dados eletrônicos e sistemas multimídia.

Essas possibilidades têm sido experimentadas em propostas educativas de utilização das novas tecnologias na perspectiva construtivista por professores, tecnólogos educacionais e elaboradores de materiais, tendo sido recentemente relatadas na literatura (veja Jonassen, 1991, Bednar et al., 1992, Hannafin et al., 1997, Boyle, 1997).

As propostas apresentadas aqui têm sido freqüentemente citadas como exemplos de aplicação do construtivismo ao desenho instrucional. Mesmo que ainda tenham que ser testadas e mais desenvolvidas, já podem ser consideradas um avanço, dada a dificuldade de implementação de seus pressupostos teóricos.

\section{Construcionismo}

O construcionismo tem suas raízes no trabalho de Seymour Papert e seu pressuposto teórico vai além da afirmação de que o conhecimento é construído pelo indivíduo, mas que isso acontece especialmente quando o indivíduo está engajado na construção de algo externo. Esse processo nos levaria a um modelo de ciclo contínuo de internalização do que está fora e de externalização do que está dentro de nós. Essa concepção vê o processo de construção de alguma coisa como intrinsecamente educacional (Boyle, 1997) e atingido por meio da disponibilização ao estudante de facilidades para criar algo. Com base no construcionismo, Beichner (1994) propõe a utilização de ferramentas de autoria com as quais o estudante pode editar sistemas multimídia para aprender ciências.

Simulações ou micromundos podem ser elaborados dentro dessa perspectiva. As simulações incorporam algum modelo de um aspecto da realidade e permitem ao usuário modificar parâmetros, executar o modelo e observar os resultados. Os micromundos são também simulações na medida em que permitem ao usuário agir sobre um "pequeno mundo". Tiveram seu grande impacto na educação por meio da linguagem de programação LOGO de Seymour Papert. A diferença entre a simulação e o micromundo consiste na forma de interação do estudante com o ambiente. No micromundo é necessário um mecanismo mediador, a 
linguagem de programação, a qual permite ao estudante agir sobre o mundo simulado. $\mathrm{O}$ aluno tem de descrever sua ação por meio de um conjunto de comandos que indiretamente representam seu raciocínio. Uma vez executados os comandos, o micromundo dá retroalimentação para a ação. Na medida que o conjunto de comandos continua acessível ao estudante, este pode rever e reformular seu raciocínio inicial em função do resultado que suas ações provocaram no micromundo.

\section{Aprendizagem baseada em Problemas}

Uma das metodologias mais fortemente apoiadas nos pressupostos construtivistas é a Aprendizagem baseada em Problemas, a qual permite ao estudante aprender a partir da colocação de um problema (ou caso), que pode ser real ou simulado (Savery \& Duffy, 1995) . Apesar de haver várias estratégias de implementação, em geral, o estudante interage com o problema, obtém dados, formula hipóteses, toma decisões e emite julgamentos. $\mathrm{Na}$ área da saúde, por exemplo, são utilizadas simulações clínicas relevantes, análogas a situações reais, que substituem problemas clínicos padronizados. A partir de perguntas, para as quais o aluno possui alternativas de respostas, e das conseqüências das decisões tomadas, ele tem a oportunidade de testar sua capacidade de julgamento frente a um conjunto de dados. As conseqüências das decisões são imediatamente simuladas pelo programa, propiciando experiência clínica em tempo relativamente curto.

Muito semelhante à Aprendizagem baseada em Problemas, a Aprendizagem baseada em Recursos (Rakes, 1996) enfatiza a interação do estudante com uma gama de recursos de aprendizagem como, por exemplo, textos, vídeos, bases eletrônicas de dados, e a Internet para resolver problemas. Essa metodologia coloca como objetivo educacional, muito mais do que a transmissão da informação ou seu armazenamento, a sua compreensão, o que inclui a busca, a análise, a avaliação e a organização da mesma. Para tal, o estudante deverá dominar todas as etapas do processo de "alfabetização" em informações (information literacy): (1) saber quando há necessidade de informação; (2) identificar a informação necessária para resolver um dado problema; (3) localizar a informação; (4) organizar a informação; (5) avaliar a informação e (6) usar a informação efetivamente para resolver o problema.

Cunningham et al. (1993) apresentam alguns princípios para a elaboração de ambientes informatizados fundamentados na Aprendizagem baseada em Problemas. Esses ambientes: (1) possibilitam que o aluno experimente o processo de construção do conhecimento, assumindo a responsabilidade pela definição dos tópicos e subtópicos do domínio a ser explorado, decidindo, dessa forma, sobre o nível de abrangência e profundidade que deseja alcançar, sobre métodos de estudo e estratégias a serem utilizadas para a solução de problemas; (2) podem oferecer experiência e múltiplas representações dos fenômenos e problemas estudados, possibilitando que o aluno avalie soluções e decisões alternativas, já que no mundo real dificilmente existe apenas uma abordagem ou uma única solução correta para um problema; (3) podem envolver a aprendizagem em contextos realistas e relevantes, mais autênticos em relação às tarefas da aprendizagem, possibilitando ao aluno vivenciar a complexidade dos fenômenos de forma mais real, aumentando a capacidade de transferência das experiências do processo de aprendizagem para o seu dia-a-dia; (4) desafiam o aluno, encorajando 
"apropriação" (ownership) e "voz" no processo de aprendizagem, deixando ao professor o papel de consultor que apenas o orienta na organização de seus objetivos e caminhos na aprendizagem; (5) encorajam e oferecem a possibilidade de uso de múltiplas formas de representação além dos meios tradicionais, para enriquecer o olhar do aluno sobre a realidade dos problemas estudados, na medida em que cada meio tem sua especificidade e linguagem e, portanto, oferece um olhar específico e parcial da realidade; (6) encorajam a autoconscientização sobre o processo de construção de conhecimento, a compreensão de como o aluno aprende e toma decisões e a capacidade de explicar por que e como um determinado problema foi resolvido, isto é, possibilitando a formação de uma atitude "reflexiva" em relação aos fenômenos e problemas do mundo real (extensão de atividades metacognitivas).

Jonassen (1998) recomenda que o problema proposto não seja totalmente estruturado, permitindo que alguns aspectos sejam definidos pelo aluno. Desse modo, não devem ser apresentadas metas explícitas e formais, nem princípios gerais para descrever ou prever circunstâncias do caso. Múltiplas soluções devem ser aceitas e múltiplos critérios de avaliação das soluções são necessários. Não devem ser dados de antemão os conceitos e princípios úteis, nem como estes se organizam para solucionar o problema. $O$ julgamento sobre 0 problema e a defesa da posição pessoal devem ser solicitados ao aluno.

Com base no argumento de que o estudante deveria ter maior responsabilidade sobre suas experiências de aprendizagem, há autores construtivistas que acreditam que o próprio aluno deveria escolher os problemas a serem estudados. Nesse caso, o papel do professor seria o de ajudá-lo a gerar problemas relevantes e interessantes para sua realidade.

\section{Aprendizagem Contextualizada}

A ênfase à característica de construção do conhecimento como um processo necessariamente contextualizado deu origem à Instrução Ancorada, que se baseia nos princípios da Cognição Situada (Brown et al., 1989). Segundo essa abordagem, a aprendizagem deve ocorrer a partir de tarefas autênticas, significativas dentro de um determinado contexto.

O objetivo da Instrução Ancorada é envolver o estudante ativamente na aprendizagem, inserindo a instrução em ambientes de resolução de problemas realísticos e na execução de tarefas freqüentemente realizadas na atividade científica. Esses ambientes não se propõem a instruí-lo, mas a fornecer uma situação onde a aprendizagem possa ocorrer. Assim, planejadores que trabalham com esses pressupostos precisam identificar os especialistas e a variedade de tarefas que eles enfrentam (Bednar et al., 1992) para projetar ambientes ricos em contexto. Esses ambientes ajudam o estudante a desenvolver habilidades e atitudes que contribuem para a resolução de problemas e a adquirir conceitos e princípios específicos que permitem a ele pensar efetivamente sobre determinados conteúdos.

A Instrução Ancorada difere da Abordagem baseada em Problemas na medida em que os contextos projetados aqui são complexos e podem ser revisitados pelo estudante em períodos longos de tempo a partir de múltiplas perspectivas. Assim, o aluno pode explorar um determinado problema, colocando-se no papel de cientista, de historiador, etc. (Brown et al., 1989). 
Nesses projetos, a tecnologia é freqüentemente usada como uma ferramenta para explorar recursos e integrar conhecimento à medida que os problemas são resolvidos ou os objetivos da aprendizagem pessoal são perseguidos. Bancos de dados e a Internet podem ser consultados para localizar as informações necessárias para resolver um problema.

Além da ligação com o contexto, a Cognição Situada também baseia-se em pressupostos de cognitivistas sociais como Vygotsky (1984), quando afirma que o estudante aprende e desenvolve-se realizando uma tarefa através da interação com os outros. Tal referencial tem servido de inspiração para a concepção de trabalho colaborativo, cujo significado é o de compartilhar objetivos com a intenção de criar algo novo através da colaboração. Nesse sentido, enfatiza-se a interação estudante-professor ou estudanteestudante para modelar ou apoiar a compreensão e o desempenho. Os meios de comunicação oferecidos pelas novas tecnologias possuem recursos que podem propiciar a interação (formal e não-formal) entre grupos, favorecendo atividades em conjunto como, por exemplo, a elaboração de textos e projetos, e as discussões de temas entre docentes e estudantes e entre os próprios estudantes.

\section{Flexibilidade Cognitiva}

A má estruturação de alguns conteúdos é apontada por Spiro et al. (1992) como uma possível causa dos obstáculos enfrentados pelo aluno de níveis avançados no domínio da complexidade conceitual e na habilidade de usar independentemente o conhecimento estruturado em novas situações.

Segundo Spiro et al. (1992), esses obstáculos podem ser superados por uma nova orientação construtivista que sugere processos construtivos de agregação flexível e específica das estruturas de conhecimento que visam a ajustar-se a novas situações. Essas considerações deram origem à Teoria da Flexibilidade Cognitiva (TFC) discutida em detalhes em Spiro et al., 1992. Essa teoria é uma nova resposta "construtivista" às dificuldades da aquisição avançada de conhecimento em conteúdos mal estruturados. É, ao mesmo tempo, teoria de aprendizagem, representação mental e instrução integrada (Spiro et al., 1992).

Como instrução, a TFC indica alguns recursos para promover a compreensão conceitual complexa e o uso adaptado do conhecimento para transferência. Um deles é o retorno do aluno ao mesmo material em diferentes oportunidades, em contextos rearranjados para diferentes propósitos e a partir de diferentes perspectivas conceituais. A justificativa para esse recurso instrucional seria o de que elementos importantes de qualquer explicação de conceito ou caso complexo poderiam ser mais visíveis em contextos diferentes ou de um ponto de vista diferente.

Outro problema, apontado pelos autores, que explicaria a maioria das falhas de aprendizagem avançada é a simplificação muitas vezes causada pelo estudo de um fenômeno com base em apenas uma perspectiva. Contra a simplificação, a TFC recomenda as abordagens múltiplas que vão desde esquemas múltiplos de organização para apresentar 0 conteúdo até representações múltiplas, do conhecimento. A metáfora que eles usam para esse modelo instrucional seria a de um espaço não-linear e multidimensional do conteúdo complexo.

De acordo com os autores, sistemas hipermídia de aprendizagem podem simular esse espaço mutidimensional e, por isso, serem meios adequados para promover a flexibilidade 
cognitiva do estudante, porque tornam possível a "navegação" entre vastas quantidades de informação de uma forma não-linear (Marchionini, 1988). Os sistemas hipermídia de aprendizagem estão de acordo com os pressupostos da TFC (Jacobson, 1994) na medida em que eles: (1) empregam casos e exemplos ricos; (2) usam múltiplas formas de representação do conhecimento; (3) ligam conceitos abstratos a exemplos; (4) demonstram complexidades e irregularidades conceituais; (5) enfatizam a natureza inter-relacionada e a forma de teia do conhecimento; (6) encorajam a reunião do conhecimento a partir de fontes conceituais diferentes e (7) promovem a aprendizagem ativa.

Os próprios autores da TFC, contudo, chamam a atenção para o fato de que implementar essa teoria não é usar o potencial da informática para conectar tudo com tudo mais (Spiro et al., 1992). Hipertextos estruturados apenas sobre essa idéia não levarão à aprendizagem e deixarão o estudante perdido em um labirinto de ligações incidentais e conexões que só fazem sentido para o seu autor. Eles sugerem que a elaboração do hipertexto seja baseada nos pressupostos da TFC que são um contraponto aos obstáculos à aprendizagem avançada de conteúdos mal estruturados. Por exemplo, pensar em como a seqüência do conteúdo apresentado deve ser rearranjada para produzir diferentes entendimentos, quando o conteúdo é relido, seria uma preocupação na elaboração de hipertextos calcada nos pressupostos da teoria. Outro aspecto dos hipertextos baseados na TFC é o uso dos casos-exemplo, que automaticamente são disponibilizados para que o usuário possa ver aplicações de determinados conceitos. O estudante pode interagir com um leque de aplicações do conceito ao mesmo tempo e examinar facilmente a variabilidade conceitual, ao invés de encontrar esporadicamente exemplos de diferentes usos do conceito, separados por grandes períodos de tempo.

A TFC tem como corolário admitir que não há uma seqüência ideal para apresentação de qualquer conteúdo organizado em um sistema hipermídia, já que a seqüência é controlada muito mais pelo leitor do que pela estrutura do texto. A base de conhecimento do indivíduo é que vai determinar a seqüência ideal para ele. Se o estudante tem estruturas de conhecimento próprias baseadas em suas experiências prévias e habilidades, a forma que ele irá escolher acessar, interagir e inter-relacionar a informação contida na base de dados irá variar de estudante para estudante. Dessa forma, o usuário passam a ser responsáveis tanto pela estrutura quanto pelo conteúdo do material aprendido (Nelson \& Palumbo, 1992).

\section{Novas Tecnologias e a Prática Pedagógica na Perspectiva Construtivista}

A escola tem-se mostrado resistente a mudanças, mesmo quando tenta incorporar meios inovadores. Em muitos casos, "a presença nas escolas de equipamentos de vídeo ou informática obedece mais ao interesse dos pais ou aos interesses comerciais de alguma empresa do que propriamente aos educacionais e didáticos" (Alonso, 1998). Em projetos de informática educativa, por exemplo, laboratórios de informática são instalados, mas o trabalho com o aluno é desenvolvido de forma desarticulada do projeto pedagógico da escola, sem o questionamento sobre sua contribuição de ordem pedagógica e sócio-cultural, o que acaba resultando no fracasso do projeto. 
É importante que a escola perceba que o valor instrumental "não está nos próprios meios, mas na maneira como se integram na atividade didática, em como eles se inserem no desenvolvimento da ação" (Alonso, 1998). Assim, um projeto de inovação tecnológica na educação deve gerar propostas comprometidas com as finalidades educativas, assumindo como essencial o sentido transformador da prática pedagógica (Candau, 1991, Maggio 1997). Nesse sentido, apresentamos, a seguir, possíveis direcionamentos da transformação necessária de elementos da prática pedagógica no contexto de projetos de inovação tecnológica na escola, que poderiam tornar mais concreta a abordagem construtivista.

\section{O papel do professor}

Embora seja consensual que a utilização das tecnologias da informação e da comunicação na educação não vai substituir o professor, reconhece-se, hoje em dia, que o trabalho docente pode ser apoiado por esses meios (Silva \& Marchelli, 1998). O trabalho do professor é fundamental nos projetos de inovações tecnológicas até porque "a qualidade educativa destes meios de ensino depende, mais do que de suas características técnicas, do uso ou exploração didática que realiza o docente e do contexto em que se desenvolve" (Liguori, 1997). Referindo-se à informática educativa e, mais recentemente, à utilização da Internet no processo educativo, vários autores discutem de que forma o papel do professor poderia adequar-se ao uso das novas tecnologias educacionais na concepção construtivista da aprendizagem.

Para Valente (1993), o professor deixa de ser o repassador do conhecimento para ser o criador de ambientes de aprendizagem e facilitador do processo pelo qual o aluno adquire conhecimento. Demo (1998), tentando redefinir o papel do professor (cuja função básica não é mais dar aula, pois isso pode ser feito através da televisão ou do microcomputador), apresentao como o orientador do processo reconstrutivo do aluno, através da avaliação permanente, do suporte em termos de materiais a serem trabalhados, da motivação constante e da organização sistemática do processo.

Moran (1998) considera que o ensino com as novas mídias deveria questionar as relações convencionais entre professores e alunos. Para tanto, define o perfil desse novo professor - ser aberto, humano, valorizar a busca, o estímulo, o apoio e ser capaz de estabelecer formas democráticas de pesquisa e comunicação.

Nas atividades pedagógicas realizadas através da Internet, Pacheco (1997) considera que professor e aluno tornam-se participantes de um "novo" jogo discursivo que não reconhece a autoridade ou os privilégios de monopólio da fala presentes, com freqüência, nas relações de ensino-aprendizagem tradicionais, inaugurando, assim, relações comunicativas e interpessoais mais simétricas.

$\mathrm{Na}$ Aprendizagem baseada em Problemas, por exemplo, a atividade mais crítica do professor (Savery \& Duffy, 1995) está relacionada com as questões que ele irá formular aos estudantes. É essencial que elas valorizem e desafiem o pensamento do aprendiz, não o induzindo sobre o que fazer ou como pensar. O mais importante, ao contrário, é que o ensino questione o pensamento do estudante. 
O papel do professor, na abordagem construtivista, aproxima-se de uma concepção de profissional que facilita a construção de significados por parte do aluno nas suas interpretações do mundo. Assim, este profissional será melhor denominado de facilitador pedagógico. Para que possa ajudar o aluno, o facilitador pedagógico, primeiramente, deverá possuir uma concepção clara da construção de conhecimento enquanto processo dinâmico e relacional advindo da reflexão conjunta sobre o mundo real. Deverá possuir base teórica consistente, clara concepção do objetivo da aprendizagem e da metodologia a ser utilizada, assim como do processo de avaliação de acordo com a visão construtivista de conhecimento (Struchiner et al., 1998).

Em sua prática, o facilitador pedagógico poderá, entre outras atividades: (I) desenvolver poucos conceitos com maior produtividade; (2) encorajar o aluno a buscar outros pontos de vista e a desejar aprender e entender; (3) propiciar a análise de experiências significativas e a sua reflexão crítica; (4) promover a comunicação entre os alunos e grupos de alunos e o intercâmbio de experiências.

$\mathrm{Na}$ realidade, as relações convencionais professor-aluno estão em pauta de discussão não só como conseqüência da visão construtivista de aprendizagem, mas também porque o professor deixou de ser o único a ter acesso à informação nessa relação. Esse dado está levando o professor a mudar de postura, abdicando do poder que detinha enquanto único possuidor do conhecimento relevante no contexto escolar, favorecendo uma relação mais simétrica com o aluno.

\section{Planejamento}

O planejamento instrucional tradicional tinha uma função primordialmente prescritiva, incluindo as etapas de análise das necessidades, seleção dos materiais e métodos instrucionais e avaliação. $\mathrm{Na}$ análise de necessidades, eram identificadas as subtarefas que deveriam ser cumpridas pelo estudante e cada parte do conhecimento que ele deveria adquirir. A partir dessa fase, os passos que o aluno deveria seguir para adquirir conhecimento podiam ser planejados. Nesse processo, surgiam os objetivos, que eram subdivididos em objetivos específicos. Os objetivos específicos eram, então, estabelecidos em termos de comportamentos observáveis e mensuráveis. A partir dos objetivos especificados, o planejador escolhia os métodos e recursos instrucionais necessários para que os objetivos fossem alcançados.

Esse tipo de planejamento, hoje considerado demasiadamente mecânico e prescritivo, é ainda seguido, por exemplo, para elaborar software educacionais tutoriais ou de exercício e prática.

A perspectiva construtivista, ao questionar a aprendizagem por uma seqüência instrucional imposta, volta-se para as formas de facilitar o processo construtivo de aprendizagem. Essa perspectiva leva a uma abordagem muito mais centrada na provisão de experiências de aprendizagem ao aluno do que no planejamento da instrução. Por não ser prescritivo, o planejamento pedagógico, no paradigma construtivista, impõe grandes desafios a serem enfrentados pelo professor, pois não há uma fórmula (e será muito difícil encontrar uma) que permita a transferência imediata de seus princípios à prática (Boyle, 1997). Esse processo exige um planejamento cuidadoso, pois romper com modelos tradicionais de ensino- 
aprendizagem não quer dizer que o planejamento seja dispensável, ao contrário, a natureza complexa das interações em ambientes tecnológicos de aprendizagem exige a articulação de princípios e modelos conceituais à criação de espaços que ofereçam suporte em diferentes experiências de aprendizagem, estimulem a participação e a meta-aprendizagem do aluno (Struchiner et al., 1998). A contextualização da aprendizagem defendida pelo construtivismo (Bednar et al., 1992) exige o planejamento de tarefas de aprendizagem inseridas em contextos de resolução de problemas que sejam relevantes no mundo real. A análise de tarefas procura evitar a decomposição das atividade de aprendizagem e passa a se preocupar com a criação de problemas contextualizados relevantes e realísticos. Preferencialmente, os problemas enfrentados têm que mostrar a relevância que as habilidades e os conhecimentos envolvidos na sua solução podem ter para a vida do aluno.

O domínio de fatos e conhecimentos, objetivo da educação tradicional, deu lugar às habilidades e aos processos necessários para tornar o aluno um especialista que pode operar construtivamente dentro de um conteúdo/contexto. O engajamento em colaboração, a apreciação de múltiplas perspectivas, a avaliação e o uso ativo do conhecimento tornam-se o alvo do planejamento.

Por isso, não faz sentido dividir o conteúdo em pequenos módulos e ordená-los de acordo com níveis crescentes de dificuldade. Da mesma forma, não é possível fazer afirmações genéricas sobre como a informação será usada pelo aluno, o que torna difícil pensar em objetivos específicos predeterminados. Ao contrário do previsto na visão tradicional, os objetivos específicos surgem na realização de tarefas autênticas e durante a resolução de problemas significativos para o estudante.

Também não basta planejar uma única tarefa ou problema. A construção do conhecimento, sendo um processo individual e particular, não permite o planejamento de tarefas únicas para um determinado perfil médio de alunos. Para atender a essa nova abordagem, é necessário que o desenho instrucional do ambiente de aprendizagem possa ajustar-se às necessidades particulares de cada aluno, o que ainda é um grande desafio para o planejamento na área de tecnologia educacional.

\section{Avaliação da Aprendizagem}

Da mesma forma que o planejamento, a avaliação, na perspectiva construtivista, é diferenciada da tradicional. Apesar de ser uma questão em aberto, há algumas diretrizes que podem orientar o processo de avaliação do desempenho do estudante em projetos educacionais com utilização de novas tecnologias nesse novo paradigma.

Se, na abordagem construtivista, o estudante irá desenvolver diferentes perspectivas da realidade por meio de processos individuais de construção do conhecimento, os processos de avaliação deveriam acomodar uma variedade mais ampla de opções de respostas aos problemas (Jonassen, 1991). Além disso, sendo priorizada a avaliação dos processos mentais do aluno em relação aos produtos finais, os conceitos de certo ou errado tornam-se secundários na medida que o aluno deve ser capaz não só de chegar a uma resposta, mas também de justificar e defender seus julgamentos e decisões durante a resolução de problemas. 
Enquanto, convencionalmente, os resultados da aprendizagem são definidos em termos do conhecimento e das habilidade adquiridos pelo estudante, os construtivistas argumentam que experimentar e tornar-se proficiente no processo do conhecimento é mais importante. Nesse sentido, uma atividade de avaliação coerente com os pressupostos construtivistas é a reflexão do estudante sobre sua própria aprendizagem e o registro do processo através do qual ele construiu sua visão do conteúdo (Bednar et al., 1992). A tendência da avaliação é servir menos como reforço ou instrumento de controle e mais como ferramenta de auto-análise (Jonassen, 1991).

Cunningham (1991) considera que a avaliação objetiva, aplicada como uma medida separada do resultado da aprendizagem, não funciona no paradigma construtivista. Ele defende a avaliação da aprendizagem em função da solução bem sucedida de uma tarefa. O julgamento da resolução do problema deve então, ser feito pelo professor, com base na consideração de todas as evidências disponíveis.

Os autores construtivistas consideram importante a avaliação da aprendizagem inserida em um contexto. Professores tradicionais também têm reconhecido que as habilidades importantes não são cobradas em testes desvinculados do contexto da aprendizagem. A procura de melhores meios de avaliação, porém, ainda é uma questão em aberto. As alternativas oferecidas pelos construtivistas ainda soam imprecisas. Elas precisam tornar-se mais claras, mostrarem-se válidas economicamente e atenderem às demandas das diferentes partes interessadas.

\section{Considerações Finais}

A incorporação das novas tecnologias da informação e da comunicação na educação tem conseqüências tanto para a prática docente como para os processos de aprendizagem. Este trabalho restringiu-se ao exame de algumas implicações, de ordem pedagógica, das inovações tecnológicas sobre a educação, portanto a uma visão parcial da situação, na medida em que não foram discutidas as condições políticas e sociais que estruturam as práticas escolares.

Mesmo sem o aprofundamento da questão político-social, não é difícil perceber que a tecnologia tem um papel de destaque no momento social que estamos vivendo. $O$ aluno de hoje, de todos os níveis de ensino, com o acesso (maior ou menor) às novas tecnologias em seu cotidiano, começa a desempenhar um novo papel no contexto escolar. Apresenta vantagens em relação ao aluno de dez anos atrás, porque traz para a escola maior conhecimento factual e demonstra necessidades e expectativas mais objetivas quanto à sua formação. Como resposta a essa realidade, é fundamental o questionamento da postura tradicional do professor enquanto detentor do poder e do conhecimento, em total descompasso com as tendências atuais de incorporação das novas tecnologias da informação e da comunicação na educação, segundo a perspectiva construtivista.

Esperamos ter deixado claro, ao longo do trabalho, que a introdução das novas tecnologias da informação e da comunicação no contexto educacional só pode significar um avanço para o cotidiano de professores e alunos, se essa aliança não se caracterizar somente pela presença da tecnologia (Dillon, 1996). Pela sucinta análise desenvolvida aqui, a relação 
entre a tecnologia educacional e a prática pedagógica pode ser de colaboração, desde que a tecnologia seja subjugada aos objetivos pedagógicos. Isso quer dizer que professores, coordenadores, elaboradores de materiais e alunos estarão discutindo o seu papel, e que esse processo poderá ser um impulso para a abertura da mentalidade dos professores (Kawamura, 1998) e para o questionamento dos paradigmas tradicionais de ensino-aprendizagem cristalizados em nossa cultura, cuja fundamentação está enraizada no objetivismo (Jonassen, 1996).

Este trabalho defende o uso da tecnologia na educação quando guiado pelas necessidades de alunos e professores e, principalmente, quando calcado em abordagens teóricas sobre a natureza do conhecimento e do processo de ensino-aprendizagem. A intenção não foi a de sugerir aos planejadores a adoção da epistemologia construtivista no uso das novas tecnologias na educação, mas a de mostrar como é possível e recomendável articular uma concepção de conhecimento e de aprendizagem a um projeto de inovação tecnológica na educação; além disso, mostrar que há alternativas nessa perspectiva sendo testadas, algumas delas apresentadas aqui.

\section{Referências}

ALONSO, Ángel San Martín. 1998. O método e as decisões sobre os meios didáticos. In: SANCHO, J.M. (Org.). Para Uma Tecnologia Educacional. Porto Alegre: Artes Médicas.

BASTOS, Fernando. 1998. Construtivismo e Ensino de Ciências. In: NARDI, Roberto. (Org.). Questões Atuais no Ensino de Ciências. SP: Escrituras Editora.

BEDNAR, Anne K., CUNNINGHAM, Donald, DUFFY, Thomas M., PERRY, J. David. 1992. Theory into Practice: How do we link? In: DUFFY, T.M., JONASSEN, D.H. (Eds.). Constructivism and the Technology of Instruction: A Conversation. London: Lawrence Erlbaum.

BEICHNER, Robert J. 1994. Multimedia editing to promote science learning. Journal of Educational Multimedia and Hypermedia, v.3, n.1, p.55-70.

BOYLE, Tom. 1997. Design for Multimedia Learning. London: Prentice Hall.

BROWN, J. S., COLLINS, A., DUGUID, P. 1989. Situated cognition and the culture of learning. Educational Researcher, v.18, p.32-42.

CANDAU, Vera M. 1991. Informática na Educação: um desafio. Tecnologia Educacional, v.20, n.98, 99, p.14-23, jan/abr.1991.

CARRAHER, David W. 1992. O papel do computador na aprendizagem. Revista Acesso, 3, n.5, p.21-30, jan.1992.

CUNNINGHAM, Donald J. 1991. Assessing constructions and constructing assessments: a dialogue. Educational Technology, v.31, n.5, p.13-17.

CUNNINGHAM, Donald J., DUFFY, Thomas M., KNUTH, Randy A. 1993. The Textbook of the Future. In: MCKNIGHT, C., DILLON, A., RICHARDSON, J. (Eds.). Hypertext: a psychological perspective. New York: Ellis Horwood.

DEMO, Pedro. 1998. Professor \& Teleducação. Tecnologia Educacional, v.26, n.143, p.52-63. 
DILLON, Andrew. 1996. Myths, Misconceptions and an Alternative Perspective on Information Usage and the Electronic Medium. In: ROUET, J.F., LEVONEN, J.J., DILLON, A., SPIRO, R.J. (Eds.). Hypertext and Cognition. NJ: Lawrence Erlbaum.

HANNAFIN, Michael, HANNAFIN, Kathleen M., LAND, Susan M., OLIVER, Kevin. 1997. Grounded Practice and the Design of Constructivist Learning Environments. Educational Technology Research \& Development, v.45, n.3.

JACOBSON, Michael J. 1994. Issues in hypertext and hypermedia research: toward a framework for linking theory-to-design. Journal of Educational Multimedia and Hypermedia, v.3, n.2, p.141-154.

JONASSEN, David. 1991. Objetivism versus Construtivism: Do We Need a New Philosophical Paradigm? Educational Technology Research \& Development, v.39, n.3, p.5-14.

JONASSEN, David H. 1996. Using Mindtools to Develop Critical Thinking and Foster Collaboration in Schools. In: JONASSEN, D.H. (Ed.). Computers in the Classroom: Mindtools for Critical Thinking. NJ: Prentice Hall.

JONASSEN, David. 1998. Designing Constructivist Learning Environments. In: REIGELUTH, C. M.. Instructional Theories and Models. 2.ed. Mahwah: Lawrence Erlbaum.

KAWAMURA, Regina. 1998. Linguagem e Novas Tecnologias. In: ALMEIDA, Maria José P.M. de, SILVA, Henrique César da. (Orgs.). Linguagens, Leituras e Ensino da Ciência. Campinas: Mercado das Letras.

LIGUORI, Laura M. 1997. As Novas Tecnologias da Informação e da Comunicação no Campo dos Velhos Problemas e Desafios Educacionais. In: LITWIN, Edith (Org.). Tecnologia Educacional - Política, Histórias e Propostas. Porto Alegre: Artes Médicas.

MAGGIO, Mariana. 1997. O Campo da Tecnologia Educacional: Algumas Propostas para sua Reconceitualização. In: LITWIN, Edith (Org.). Tecnologia Educacional - Política, Histórias e Propostas. Porto Alegre: Artes Médicas.

MARCHIONINI, Gary. 1988. Hypermedia and learning: freedom and chaos. Educational Technology, v.28, n.110, p.8-12, nov.1988.

MONTEIRO, Eduardo B., REZENDE, Flavia. 1993. Informática e Educação: panorâmica da área segundo artigos dos periódicos nacionais de educação. Tecnologia Educacional, v.22, n.110, 111, p.42-49, jan/abr.1993.

MORAN, José Manuel. 1998. Internet no ensino universitário: pesquisa e comunicação na sala de aula. Interface - Comunicação, Saúde, Educação, n.3, ago.1998.

MORGAN, Alistair R. 1995. Student Learning and Student's Experiences: Research, Theory and Practice. In: LOCKWOOD, Fred (Ed.). Open and Distance Learning Today. London and New York: Routledge.

NELSON, Wayne A., PALUMBO, David B. 1992. Learning, instruction and hypermedia. Journal of Educational Multimedia and Hypermedia, v.1, p.287-299.

PACHECO, Samuel Bueno. 1997. Internet: as relações de ensino-aprendizagem no hiperespaço. Tecnologia Educacional, v.25, n.136, 137, mai/jun/jul/ago.1997.

PERKINS, David N. 1992. Technology Meets Constructivism: Do They Make a Marriage? In: DUFFY, T.M., JONASSEN, D.H. (Eds.). Constructivism and the Technology of Instruction: A Conversation. NJ: Lawrence Erlbaum. 
PRETTO, Nelson. 1996. Uma escola sem/com futuro - educação e multimídia. Campinas: Papirus.

RAKES, Glenda C. 1996. Using the Internet as a tool in a resource-based learning environment. Educational Technology, sep/oct.1996.

SANCHO, Juana. A 1998. Tecnologia: Um Modo de Transformar o Mundo Carregado de Ambivalência. In: SANCHO, J.M. (Org.). Para Uma Tecnologia Educacional. Porto Alegre: Artes Médicas.

SAVERY, John R., DUFFY, Thomas M. Problem Based Learning: an instructional model and its constructivist framework. Educational Technology, sep-oct.1995.

SILVA, Dirceu, MARCHELLI, Paulo Sérgio. 1998. Informática e Linguagem: Análise de Softwares Educativos. In: ALMEIDA, Maria José P.M. de, SILVA, Henrique César da. (Orgs.). Linguagens, Leituras e Ensino da Ciência. Campinas: Mercado de Letras.

SPIRO, Rand J., FELTOVITCH, Paul J., JACOBSON, Michael J., COULSON, Richard L. 1992. Cognitive Flexibility, Constructivism and Hypertext: Random Access Instruction for Advanced Knowledge Acquisition in III-Structured Domains. In: DUFFY, T.M., JONASSEN, D.H. (Eds.). Constructivism and the Technology of Instruction: A Conversation. NJ: Lawrence Erlbaum.

STRUCHINER, Miriam, REZENDE, Flavia, RICCIARDI, Regina M. V., CARVALHO, Maria Alice P. de. 1998. Elementos Fundamentais para o desenvolvimento de ambientes construtivistas de aprendizagem a distância. Tecnologia Educacional, v.26, n.142, p.311, jul/ago/set.1998.

VALENTE, José A. 1993. Diferentes usos do computador na Educação. Em Aberto, Brasília, 12, n.57, p.3-16, jan/mar.1993.

VYGOTSKY, L. 1984. A Formação Social da Mente: O Desenvolvimento dos Processos Psicológicos Superiores. São Paulo: Martins Fontes.

\begin{abstract}
This paper discusses, within a constructivist framework, the use of new information and communication technologies in the educational process, indicating the consequent challenges posed to instructional design and teaching practice. An overview is given of how the constructivist approach can affect both materials and teaching practices which rely upon such new technologies. From the same perspective, the discussion develops some considerations regarding consequent modifications in the educational aspects of school environment, for example, the role of the teacher and the assessment within projects involving technological innovation. The chief aim of the present work is to provide a review of how this topic has been presented in Brazilian and foreign educational publications, which it is hoped may be of help to those interested in recent trends in the introduction of new technologies in education.
\end{abstract}

\title{
Correspondência:
}

Flavia Rezende, Laboratório de Tecnologias Cognitivas, NUTES - Núcleo de Tecnologia Educacional para a Saúde, Universidade Federal do Rio de Janeiro; Centro de Ciências da Saúde, 
Bloco A, sala 26. Av. Brig. Tropowsky, s/n - Cidade Universitária, Ilha do Fundão, Rio de Janeiro, RJ - cep 21949-900. Correio eletrônico: frezende@ nutes.ufrj.br 